\title{
Over-shading is critical for inducing a regime shift from heathland to grassland under nitrogen enrichment
}

\author{
G.A.K. van Voorn ${ }^{\text {a,* }}$, B.W. Kooi ${ }^{\text {b }}$, A.K. Bregt ${ }^{c}$ \\ ${ }^{a}$ Biometris, Wageningen University and Research Centre, Droevendaalsesteeg 1, 6708 PD Wageningen, The Netherlands \\ ${ }^{\mathrm{b}}$ Faculty of Earth and Life Sciences, VU University, de Boelelaan 1085, 1081 HV Amsterdam, The Netherlands \\ ${ }^{\mathrm{c}}$ Laboratory of Geo-Information, Science and Remote Sensing, Wageningen University, Droevendaalsesteeg 3, 6708 PB Wageningen, The Netherlands
}

\section{A R T I C L E I N F O}

\section{Article history:}

Received 19 December 2014

Received in revised form 28 July 2015

Accepted 12 August 2015

Available online 3 September 2015

\section{Keywords:}

Heathland conversion

Nitrogen enrichment

Synthesizing Unit

Regime shift

Competition model

\begin{abstract}
A B S T R A C T
The mass conversion of heathland to grassland in north-western Europe the past decades is a typical example of how tipping points threaten the biodiversity and ecosystem services delivered by biota. Different explanations have been provided for this conversion, with nitrogen enrichment resulting from anthropogenic activities being a commonly supported hypothesis. Here we present a mathematical model to investigate the conditions under which the conversion of heathland to grassland can occur. The model describes indirect competition for light and nitrogen between heather dwarf shrub (Calluna vulgaris) and wavy hair-grass (Deschampsia flexuosa), while both species also over-shade each other. Nutrient co-limitation in the model is described using the Synthesizing Unit concept. Over-shading is found to play a pivotal role in the existence of alternative stable states in the model. Under constant light availability a combination of over-shading and enrichment with ammonia leads to a regime shift from heathland to grassland, while under enrichment with ammonia alone there is coexistence between the two species. These results are supported by experimental findings in the literature.
\end{abstract}

(c) 2015 Elsevier B.V. All rights reserved.

\section{Introduction}

A major conservation issue nowadays is the loss of biodiversity and the subsequent loss of ecosystem services provided by biota via regime shifts or tipping points (Folke et al., 2004; Scheffer et al., 2009; Boettiger et al., 2013). Regime shifts are fast and large-scale changes caused by relatively small changes in system drivers, often because of direct or indirect anthropogenic influences, resulting from the existence of nonlinear interactions and feedbacks (Scheffer and Carpenter, 2003). The complexities surrounding the conditions under which tipping points occur pose a significant challenge for future environmental policy and management but have to be considered (Folke et al., 2004; Schlüter et al., 2012).

An interesting case study in this regard may be the large-scale conversion of heathland to grassland. Heathland is an ecosystem type that provides unique ecosystem services, such as a high conservational value for biota and a high aesthetic and historical value (Alonso et al., 2001), while it historically provided grazing

\footnotetext{
* Corresponding author at: P.O. Box 16, 6700 AA Wageningen, The Netherlands. Tel.: +31 317484616 .

E-mail addresses: george.vanvoorn@wur.nl (G.A.K. van Voorn), bob.kooi@vu.nl (B.W. Kooi).
}

terrain for sheep. It has also been suggested that heathland may be used as a source of bioenergy production (Worrall and Clay, 2014). Experimental studies have suggested that the dynamics of the heathland plant community may be considered as essentially a twospecies system consisting of heather dwarf shrub (Calluna vulgaris) and wavy hair-grass (Deschampsia flexuosa) (Damgaard et al., 2009). Normally heathland is dominated by Calluna, but since the 70 s and 80 s of the last century mass replacements have occurred in northwestern Europe (UK, The Netherlands) of Calluna by Deschampsia, while further losses of heathland have occurred due to a combination of afforestation and poor management (Cadbury, 1992).

Several theories have been suggested to explain the mass shifts from heathland to grassland. Wavy hair-grass occurs naturally in heathland, in particular after heather dieback caused by infestation by heather beetle (Lochmaea suturalis). It therefore has been suggested that heathland can naturally change to grassland through beetle infestation alone (Berdowski, 1987). Nevertheless, grasses seldom outgrow Calluna under pre-industrial or even mildly elevated nitrogen availability levels (Alonso et al., 2001). This may perhaps be because of specific grazing by ungulates like sheep and deer (Alonso et al., 2001), which may target grasses more than Calluna.

The dominant view in ecological literature is that nitrogen enrichment is the main driver in heathland conversion to grassland 
in the Netherlands (Heil and Bobbink, 1993) and the UK (Power et al., 1998). Replacement of Calluna by grasses does occur in experiments with significant nitrogen enrichment (Heil and Diemont, 1983). The concept of critical load has been introduced to provide threshold values above which nitrogen deposition rates start to have observable negative effects on ecosystem communities (Bobbink et al., 2011). In the UK wet deposition of nitrogen has increased from around 2-6 kg nitrogen per hectare per year in the 1900s to around $15-60 \mathrm{~kg}$ in the 1990s (Pitcairn et al., 1995). In the Netherlands nitrogen deposition levels are predicted to be as high as 14001800 mol per hectare per year over the period 2010-2030 (Velders et al., 2010), which translates to an average of ca. $22 \mathrm{~kg}$ per hectare per year. An exceedance by $500-1500 \mathrm{~mol}$ (ca. $10 \mathrm{~kg}$ ) per hectare per year in many of the NATURA2000 areas in the Netherlands is predicted (Velders et al., 2010). Such numbers indicate at least that nitrogen deposition will have effects, although it does not directly explain a shift from heathland to grassland.

Another factor that has been suggested to be of importance is competition for light between the two species (Van der Eerden et al., 1991; Britton et al., 2003), but only under gap formation resulting from e.g. grazing (Aerts et al., 1990). Experiments with Calluna show that shading leads to strong reduction of flowering, etiolating of shoots, and lower shoot densities, while nitrogen enrichment leads to increased flowering (Iason and Hester, 1993). Other observations suggest that Calluna with an intact canopy can out-compete grasses, even at increased levels of nutrient supply (Alonso et al., 2001), while grown as seedlings Deschampsia always outcompetes Calluna. These observations could be explained by over-shading playing an important role in the inter-specific competition, possibly leading to priority effects (i.e., bistability or alternative steady states; Drake, 1991). Other experimental results suggest that (mostly) one-sided competition by grasses towards Calluna may indeed be associated with over-shading (Britton et al., 2003).

In this paper we investigate under which conditions heathland can change to grassland by looking at the combined effects of competition for nitrogen and light between Calluna and Deschampsia on the respective species populations. For this we develop a mathematical model consisting of a set of ordinary differential equations which is based on stylized facts that have been put together from various literature sources. The competition for light and nitrogen is indirect and incorporated by describing colimitation of light and nitrogen sources (ammonium, nitrate) available to Calluna and grass by making use of the Synthesizing Unit formulation (Kooijman, 2010). Light availability is constant but for the two species it is affected by over-shading. Phosphorus limitation has been suggested to be of relevance as well, but experiments with nitrogen and phosphorus enrichment of C. vulgaris have not indicated a clear phosphorus limitation (Von Oheimb et al., 2010), hence we do not include phosphorus in the model.

The paper is organized as follows. In Section 2 we provide the description of the conceptual model and discuss the stylized facts (in Table 1) and important assumptions and simplifications (in Table 2). In Section 3 the mathematical model is given, which is a set of ordinary differential equations. The derivation of the functional responses of the model based on the Synthesizing Unit concept is given in Appendix A. The model is analyzed in Section 4 by primarily using bifurcation analysis. Section 5 presents the discussion and conclusions.

\section{Conceptual model}

The model describes Calluna and grass which are co-limited by light and nitrogen (ammonium and nitrate). The graphical depiction of the conceptual model is given in Fig. 1. Conceptually the system
Table 1

Stylized facts about heather and grass taken from literature.

\begin{tabular}{|c|c|}
\hline No. & Short description and source \\
\hline I & $\begin{array}{l}\text { Deschampsia significantly affects Calluna but not the other way } \\
\text { around. However, intra-specific competition for Deschampsia occurs } \\
\text { at planting densities above } 29 \text { plants } \mathrm{m}^{-2} \text {, while Calluna does not } \\
\text { show clear intra-specific competition (Britton et al., 2003) }\end{array}$ \\
\hline II & $\begin{array}{l}\text { Calluna is slow-growing but evergreen and with an intact canopy can } \\
\text { outcompete grasses, even at increased levels of nutrient supply } \\
\text { (Alonso et al., 2001). When grown as seedlings Deschampsia always } \\
\text { outcompetes Calluna }\end{array}$ \\
\hline III & $\begin{array}{l}\text { Calluna competes best on sandy soil, where the shoot biomass ratio is } \\
\text { greatest (Britton et al., 2003) }\end{array}$ \\
\hline IV & $\begin{array}{l}\text { Grasses (including Deschampsia) typically utilize surface water and } \\
\text { surface nitrogen, which is ammonium. Shrubs (including Calluna) } \\
\text { typically utilize deeper water and deep soil nitrogen, which is } \\
\text { (leached) nitrate (Gherardi et al., 2013) }\end{array}$ \\
\hline V & $\begin{array}{l}\text { Shrubs have a higher nitrate uptake rate than grasses, while their } \\
\text { ammonium uptake rates are similar (Gherardi et al., 2013) }\end{array}$ \\
\hline VI & $\begin{array}{l}\text { Young Calluna and grass individuals respond only significantly to soil } \\
\text { type (peat vs. sandy soil), and not to nitrogen additions or watering } \\
\text { regimes (Britton et al., 2003) }\end{array}$ \\
\hline VII & $\begin{array}{l}\text { Calluna seedling germination depends highly on damp conditions } \\
\text { (Britton et al., } 2003 \text { and references therein) }\end{array}$ \\
\hline VIII & $\begin{array}{l}\text { Calluna canopy is most dense if the individuals are of medium age; } \\
\text { young Calluna still needs to grow, while older Calluna shows gaps in } \\
\text { its canopy (Alonso et al., 2001) }\end{array}$ \\
\hline IX & $\begin{array}{l}\text { Fencing (which prevents grazing by deer and sheep) increases the } \\
\text { height of Calluna; Calluna typically has a height of } 0.2-2 \mathrm{~m} \text { (Alonso } \\
\text { et al., 2001) }\end{array}$ \\
\hline $\mathrm{X}$ & $\begin{array}{l}\text { Fencing and experimental nitrogen addition both roughly equally } \\
\text { contribute to increase in Deschampsia height (Alonso et al., 2001) }\end{array}$ \\
\hline $\mathrm{XI}$ & $\begin{array}{l}\text { Grazing seems to occur mostly at the rim of Calluna canopy. Grazers } \\
\text { prefer grass because of the higher palatability as compared to Calluna, } \\
\text { which contains relatively many phenolics (Alonso et al., 2001) }\end{array}$ \\
\hline XII & $\begin{array}{l}\text { Ammonium barely leaches, although there are some losses through } \\
\text { volatilization. Ammonium is nitrified to nitrite and nitrate by } \\
\text { microorganisms. Nitrate, in turn, easily leaches to surface or deeper } \\
\text { soil waters ( } \mathrm{Ri} \text { and Prentice, 2008) }\end{array}$ \\
\hline
\end{tabular}

resembles a food web model consisting of resources and consumers. For the development of the conceptual model we make use of various stylized facts that are based on observations and experimental findings published in the peer-reviewed literature. These can be found in Table 1.

Table 2

Overview of the main assumptions and simplifications of the food web model of heather and grass.

\begin{tabular}{ll}
\hline No. & Short explanation \\
\hline 1 & $\begin{array}{l}\text { All nitrogen deposition in natural areas is in the form of ammonia, i.e., } \\
\text { there is no appreciable influx of nitrate }\end{array}$ \\
& $\begin{array}{l}\text { Any chemical side-effects from nitrogen deposition are ignored in the } \\
\text { regime shift, like soil acidification and the mobilization of toxic } \\
\text { compounds such as aluminium } \\
\text { There is no limitation in the processes resulting from microbial } \\
\text { activity, i.e., nitrate formation from ammonium and re- } \\
\text { mineralization of dead biomass } \\
\text { There is no distinction between different soil layers. The fact that } \\
\text { Calluna extracts nitrogen mainly from deeper layers (in the form of } \\
\text { nitrate) is represented by a higher uptake rate for nitrate } \\
\text { Light intensity ( } L \text { ) cannot change and is homogeneous, hence } L \text { is not a } \\
\text { dynamic state variable but a parameter in the model } \\
\text { Nitrogen is the only limiting element, and hence all (bio)masses are } \\
\text { expressed in terms of } N \text {-mol. There is a fixed ratio assumed of } \\
\text { carbohydrates-to-nitrogen in the creation of biomass, i.e., there is a } \\
\text { fixed conversion factor of light } \\
\text { Grazing by herbivores and infestation by heather beetle are ignored } \\
\text { Any stoichiometric differences between dead material from grasses } \\
\text { and Calluna are ignored, i.e., dead material consists of only one type. } \\
\text { Hence the re-mineralization of dead material is perfect, and there is } \\
\text { no distinction between labile and recalcitrant components } \\
\text { Water is not a limiting factor }\end{array}$ \\
\hline
\end{tabular}




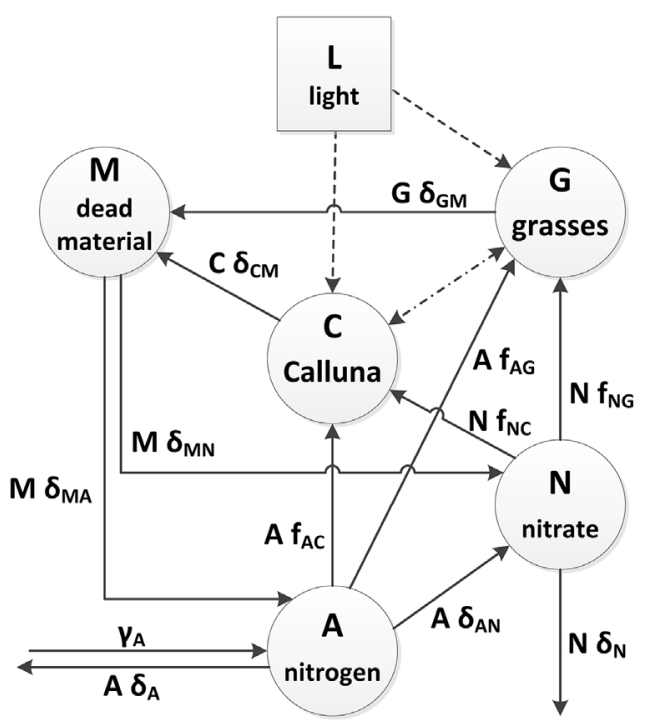

Fig. 1. A flow diagram of the conceptual model of a heathland system. Variables are indicated by circles, and variables that are kept fixed (light) by squares. Solid arrows indicate flows between compartments, and dashed lines indicate that a fixed variable affects variables. The dashed-dotted double-headed line indicates the overshading effect between heather (Calluna) and grass (Deschampsia). Nitrogen enrichment of natural areas occurs via ammonia deposition because of anthropogenic activities (nitrate is soluble and hence there is no atmospheric deposition of nitrate). Deposited ammonia undergoes volatilization, uptake by plants, and nitrification to nitrate by microbes. Nitrate leaves the system via leaching. Both plant species take up ammonium and nitrate, and deliver dead biomass that is transformed into nitrogen again by microbial activity. Symbols are explained in Table 3.

Light is the first resource. There are no fluctuations assumed in the light availability, and hence light is a model parameter. Nitrogen is the second resource, which is available to plants (the consumers) in two forms, namely nitrate and ammonium. Ammonia $\left(\mathrm{NH}_{3}\right)$ enters nature areas via the atmospheric deposition of airborne particles resulting from e.g. the volatilization of fertilizers used in agricultural areas. The ammonia then reacts with water to form ammonium $\left(\mathrm{NH}_{4}^{+}\right)$, which binds to the soil organic matter (Di and Cameron, 2002; Ri and Prentice, 2008). Microbes can convert ammonium to nitrate $\left(\mathrm{NO}_{3}^{-}\right)$. Nitrate in turn is taken up by plants, subject to leaching to deeper soil layers or surface water, or further denitrification (Di and Cameron, 2002; Ri and Prentice, 2008).

The plant species take up both types of nitrogen, but with a certain preference. Grasses typically utilize surface water and surface nitrogen, which is ammonia, while shrubs (such as Calluna) root deeper and thus typically have access to leached nitrate. Experimental results suggest furthermore that shrubs have a higher nitrate uptake rate than grasses, while their ammonium uptake rates are similar (Gherardi et al., 2013). Alonso et al. (2001) found that Calluna performs better on sandy soils. As the soil retention capacity for nutrients and water of sandy soils is limited higher uptake rates would provide a competitive advantage for shrubs.

Competition between Calluna and Deschampsia seems to be mostly one-sided (fact I). Although the mechanisms by which plants can interact physically are limited, over-shading of Calluna by grass may play a role as grass biomass increases, which results in part of the biomass physically reducing the amount of light available for Calluna.

Plants constantly produce dead biomass, which is re-mineralized to ammonium and nitrate by microbial activity, generating a partly closed-loop system. Microbial activity rates are assumed to be non-limiting in the model (assumption 3). There is no distinction between dead material coming from Calluna or grass, and no distinction between labile and recalcitrant components in this dead material (assumption 8). The death rate of grass is considered to be higher than that of the evergreen Calluna because relatively more grass above-ground biomass is lost during winter months.

\section{Mathematical model description}

For the mathematical model we consider various model foundations (assumptions and simplifications). These are listed in Table 2 . The model equations read as

$$
\begin{aligned}
& \frac{d A}{d t}=\gamma_{A}+c_{M A} \delta_{M A} M-\left(\delta_{A}+\delta_{A N}\right) A-I_{A C} f_{A C} C-I_{A G} f_{A G} G, \\
& \frac{d N}{d t}=c_{A N} \delta_{A N} A+c_{M N} \delta_{M N} M-I_{N C} f_{N C} C-I_{N G} f_{N G} G-\delta_{N} N, \\
& \frac{d C}{d t}=\left(\mu_{A C} f_{A C}+\mu_{N C} f_{N C}\right) C-\delta_{C M} C, \\
& \frac{d G}{d t}=\left(\mu_{A G} f_{A G}+\mu_{N G} f_{N G}\right) G-\delta_{G M} G, \\
& \frac{d M}{d t}=c_{C M} \delta_{C M} C+c_{G M} \delta_{G M} G-\left(\delta_{M A}+\delta_{M N}\right) M,
\end{aligned}
$$

where $A$ indicates ammonium concentration, $N$ nitrate concentration, $C$ Calluna density, $G$ grass density, and $M$ dead material from both plant species. Eqs. (1a)-(1e) represent an open system with recycling and with monitoring of mass balance. There is influx of atmospheric ammonia (the deposition rate $\gamma_{A}$ ) as well as outflux, both direct $\left(\delta_{A}\right)$ and through microbial conversion to nitrate $\left(\delta_{A N}\right)$. There is also direct outflux of nitrate $\left(\delta_{N}\right)$ e.g. by soil water. In various places in the model stoichiometric conversion parameters $\left(c_{\times \times}\right)$are required to ensure that the dimensions of all model terms match. For model simulations it is sufficient to put all conversion parameters to 1 , where we assume that all elements besides nitrogen are non-limiting, and all (bio)masses are expressed in terms of $N$-mol. A comprehensive overview of the model variables and parameters is given in Table 3 .

Competition between the two plant species for nutrients and light $L$ occurs indirectly via the uptake of nutrients and light. This is formalized in Eqs. (1a)-(1e) through scaled, dimensionless functional responses given as

$$
\begin{aligned}
& f_{A C}=b_{A C} A b_{L C} L_{C} k_{L N C}\left(b_{A C} A+b_{L C} L_{C}+b_{N C} N\right) \Theta_{C}^{-1}, \\
& f_{A G}=b_{A G} A b_{L G} L_{G} k_{L N G}\left(b_{A G} A+b_{L G} L_{G}+b_{N G} N\right) \Theta_{G}^{-1}, \\
& f_{N C}=b_{N C} N b_{L C} L_{C} k_{L A C}\left(b_{A C} A+b_{L C} L_{C}+b_{N C} N\right) \Theta_{C}^{-1}, \\
& f_{N G}=b_{N G} N b_{L G} L_{G} k_{L A G}\left(b_{A G} A+b_{L G} L_{G}+b_{N G} N\right) \Theta_{G}^{-1},
\end{aligned}
$$

where $\Theta_{\times}$is a lengthy expression that is explained in more detail in Appendix A. Light influx $L$ is assumed to be constant and treated as a parameter. The functional responses Eqs. (2a)-(2d) are based on the concept of the Synthesizing Unit (Kooijman, 2010), which assumes a time scale separation between nutrient uptake dynamics and population dynamics. Because the resources are partly complementary (light, nitrogen) and partly substitutable (nitrate, ammonium) these functional responses are more complex than the standard Holling type II functional response typically used to describe predator-prey interactions in ecological models. Under the condition of $L_{C}=L_{G}=L$ and unlimited nutrient availability Eqs. (2a)-(2d) converge to either zero or standard Holling type II 
Table 3

Parameters and state variables of the model. Dimensions are expressed as S dimensions: $T=$ time, $L=$ length, $M=$ mass. The underscores for mass $M$ indicate the type of mass. As we deal with an ODE model, surface area is assumed to remain fixed and thus functions as a scalar. The parameters $\gamma_{A}, \delta_{N}, \alpha_{C G}$, and $\alpha_{G C}$ are varied in the model analysis.

\begin{tabular}{|c|c|c|c|}
\hline Symbol & Dimension & Value & Description \\
\hline$A$ & $M_{A} L^{-2}$ & - & Soil ammonium $\left(\mathrm{NH}_{4}^{+}\right)$density \\
\hline$N$ & $M_{N} L^{-2}$ & - & Soil nitrate $\left(\mathrm{NO}_{3}^{-}\right)$density \\
\hline C & $M_{C} L^{-2}$ & - & Calluna biomass density \\
\hline G & $M_{G} L^{-2}$ & - & Grasses biomass density \\
\hline$M$ & $M_{M} L^{-2}$ & - & Detritus density \\
\hline$L$ & $M_{L} L^{-2}$ & 10 & Light influx density \\
\hline$\alpha_{C G}$ & $M_{G}^{-2} L$ & - & Over-shading of $C$ by $G$ \\
\hline$\alpha_{G C}$ & $M_{C}^{-2} L$ & - & Over-shading of $G$ by $C$ \\
\hline$c_{M A}$ & $M_{A} M_{M}^{-2}$ & 1 & $\begin{array}{l}\text { Stoichiometric conversion from } \\
M \text { to } A\end{array}$ \\
\hline$c_{A N}$ & $M_{N} M_{A}^{-1}$ & 1 & $\begin{array}{l}\text { Stoichiometric conversion from } \\
\text { A to } N\end{array}$ \\
\hline$c_{M N}$ & $M_{N} M_{M}^{-1}$ & 1 & $\begin{array}{l}\text { Stoichiometric conversion from } \\
M \text { to } N\end{array}$ \\
\hline$c_{C M}$ & $M_{M} M_{C}^{-1}$ & 1 & $\begin{array}{l}\text { Stoichiometric conversion from } \\
C \text { to } M\end{array}$ \\
\hline$c_{G M}$ & $M_{M} M_{G}^{-1}$ & 1 & $\begin{array}{l}\text { Stoichiometric conversion from } \\
G \text { to } M\end{array}$ \\
\hline$\gamma_{A}$ & $M_{A} L^{-2} T^{-1}$ & - & Ammonia input rate \\
\hline$\delta_{A}$ & $T^{-1}$ & 0 & Ammonia volatilization rate \\
\hline$\delta_{A N}$ & $T^{-1}$ & 2 & Ammonia nitrification rate \\
\hline$\delta_{N}$ & $T^{-1}$ & - & Nitrate leaching rate \\
\hline$\delta_{C M}$ & $T^{-1}$ & 0.014 & Mortality rate Calluna \\
\hline$\delta_{G M}$ & $T^{-1}$ & 0.023 & Mortality rate grass \\
\hline$\delta_{M A}$ & $T^{-1}$ & 0.05 & Ammonia re-mineralization rate \\
\hline$\delta_{M N}$ & $T^{-1}$ & 0.05 & Nitrate re-mineralization rate \\
\hline$I_{A C}$ & $M_{A} M_{C}^{-1} T^{-1}$ & 0.1 & $\begin{array}{l}\text { Maximum ingestion rate } C \text { on } A ; \\
I_{A C}=k_{L A C}\end{array}$ \\
\hline$I_{A G}$ & $M_{A} M_{G}^{-1} T^{-1}$ & 0.5 & $\begin{array}{l}\text { Maximum ingestion rate } G \text { on } A \text {; } \\
I_{A G}=k_{L A G}\end{array}$ \\
\hline$I_{N C}$ & $M_{N} M_{C}^{-1} T^{-1}$ & 0.4 & $\begin{array}{l}\text { Maximum ingestion rate } C \text { on } N \text {; } \\
I_{N C}=k_{L N C}\end{array}$ \\
\hline$I_{N G}$ & $M_{N} M_{G}^{-1} T^{-1}$ & 0.2 & $\begin{array}{l}\text { Maximum ingestion rate } G \text { on } N \text {; } \\
I_{N G}=k_{L N G}\end{array}$ \\
\hline$v_{A C}$ & $M_{A}^{-1} M_{C}$ & 0.25 & Yield of $C$ on $A$ \\
\hline$v_{A G}$ & $M_{A}^{-1} M_{G}$ & 0.35 & Yield of $G$ on $A$ \\
\hline$v_{N C}$ & $M_{N}^{-1} M_{C}$ & 0.25 & Yield of $C$ on $N$ \\
\hline$v_{N G}$ & $M_{N}^{-1} M_{G}$ & 0.35 & Yield of $G$ on $N$ \\
\hline$\mu_{A C}$ & $T^{-1}$ & 0.025 & $\begin{array}{l}\text { Maximum growth rate of } C \text { on } A \text {; } \\
\mu_{A C}=v_{A C} I_{A C}\end{array}$ \\
\hline$\mu_{A G}$ & $T^{-1}$ & 0.175 & $\begin{array}{l}\text { Maximum growth rate of } G \text { on } A \text {; } \\
\mu_{A G}=v_{A G} I_{A G}\end{array}$ \\
\hline$\mu_{N C}$ & $T^{-1}$ & 0.1 & $\begin{array}{l}\text { Maximum growth rate of } C \text { on } N \text {; } \\
\mu_{N C}=v_{N C} I_{N C}\end{array}$ \\
\hline$\mu_{N G}$ & $T^{-1}$ & 0.07 & $\begin{array}{l}\text { Maximum growth rate of } G \text { on } N \text {; } \\
\mu_{N G}=\nu_{N G} I_{N G}\end{array}$ \\
\hline
\end{tabular}

functional responses. See Appendix A for more details on the derivation of Eqs. (2a)-(2d).

Over-shading is considered in the model as an additional and direct form of competition over light $L$. Because of the possibility of unequal over-shading, a distinction is made between the light availability for Calluna $L_{C}$ and the light availability for grasses $L_{G}$. The light availability in Eqs. (2a)-(2d) is given as

$L_{C}=\operatorname{Lexp}\left(-\alpha_{C G} G\right)$

$L_{G}=\operatorname{Lexp}\left(-\alpha_{G C} C\right)$

where an exponential extinction as a function of biomass of the competing species is assumed. The parameters $\alpha_{C G}$ and $\alpha_{G C}$ in Eqs. (3a) and (3b) are non-negative parameters; growth inhibition caused by over-shading is thus modelled by taking values of $\alpha_{\times \times}>0$.

\section{Model analysis}

\subsection{Expected behaviour based on model comparison}

The full model of Eqs. (1a)-(1e), Eqs. (2a)-(2d), and Eqs. (3a) and ( $3 b)$ is rather complex - in particular due to the functional responses obtained by time-scale separation - and intractable for full algebraic analysis. It has a high number of quantities (variables and parameters) with dimensions, and making the model dimensionless results in the elimination of only a few of these because of the Buckingham Pi theorem (Bluman and Kumei, 1989). It is hence not expected that much is gained by making the model non-dimensional. Instead, expectations about the behaviour of the model can be based on the comparison of (limit cases of) the model to known food web models.

The full model resembles food chain models that include omnivory (McCann et al., 1998). Nitrate $N$ can be viewed as a 'feeder' on ammonium $A$, while Calluna and grass consume both $N$ and its 'food source' $A$. Food chain models are known to be stabilized by omnivory, where stabilization means that steady states remain stable and more complex dynamics such as periodic behaviour (limit cycles) and chaos are avoided (McCann et al., 1998). Based on this comparison our first expectation is that more complex dynamics do not occur in the model.

Our 'omnivory'-like model can be converted to a food chain model with only links between adjacent trophic levels. This is achieved by putting $\delta_{A N}=0, \delta_{M N}=0, b_{N C}=b_{N G}=0$, and $\delta_{N}=0$ in Eqs. (2a)-(2d), effectively removing $N$ from the model equations. An alternative reduced model is obtained by setting $b_{A C}=b_{A G}=0$, which mimics a lack of uptake of $A$ by Calluna and grass, effectively decoupling the upper and lower trophic levels. Food chain models are well-known for their rich, complex behaviour. However, this behaviour occurs when the bottom level of the food chain is self-replicating, which is typically when it is biotic. In food chain models of two competing species and one abiotic i.e., not self-replicating - resource there is always exclusion of one of the two competing species (Kot, 2001, Chapter 12), which eliminates the possibility for more complex behaviour. As our full model has two abiotic levels $(A$ and $N$ ) and one biotic level ( $C$ and $G$ ), we can expect that the 'reduced' versions of our model always display mutual exclusion (numerical results not shown).

For the full model one also has to consider the effect of the functional responses. Eqs. (2a)-(2d) with Eqs. (3a) and (3b) are nonlinear but do not display alternative fixed points. In fact, the limit cases of these functional responses correspond to the wellknown Holling type II functional response (see Eq. (6) in Appendix A), which is the functional response used in the original analysis by Kot (2001). All in all, because of the 'omnivory' it is expected that the full model of Eqs. (1a)-(1e), Eqs. (2a)-(2d), and Eqs. (3a) and (3b) may display coexistence between Calluna and grass, but because of the abiotic lower levels more complex behaviour like limit cycles and chaos is not expected.

\subsection{Numerical analysis methodology}

To confirm the expectations of the behaviour of the full model we focus on the asymptotic behaviour, i.e., we use bifurcation analysis and consider the stability properties of steady states. Because the model is rather intractable we perform numerical bifurcation analysis with the program Auto (Doedel and Oldeman, 2009). The program is based on the continuation of steady states in spatially homogeneous models as function of one or more parameters, and is capable of detecting the two main types of tipping points (as defined by for instance Schröder et al., 2005) by: 
1 Monitoring certain test functions to locate bifurcations, i.e., specific parameter settings at which the stability properties of steady states change;

2 Determining numerical values of saddle steady states at specific user-defined parameter settings which function as a so-called 'separatrix', i.e., the boundary in state space that separates two domains of attraction associated with two alternative stable states.

The steady states and bifurcations that are found with the help of AuTo are verified by using Maple (Maplesoft, 2014). Identical parameter values are substituted in the model equations implemented in MAPLE for independent and direct calculations of steady states. Bifurcation points can be verified by substitution of the steady state and associated parameter values in the Jacobian matrix and the subsequent calculation of the eigenvalues, i.e., MAPLE should for instance give a zero eigenvalue for the specific parameter values for which AUTo has located a tangent bifurcation.

Further information about the basics of bifurcation analysis can be found in e.g. Guckenheimer and Holmes (1985), Wiggins (1990), Kuznetsov (2004), and Seydel (2010), and examples of ecological applications of bifurcation analysis in for instance Bazykin (1998), Kooi (2003), Van Voorn et al. (2007), Van Voorn et al. (2010), and Kooi et al. (2011).

\subsection{Numerical analysis results}

The main results of the numerical bifurcation analysis of the full model of Eqs. (1a)-(1e), Eqs. (2a)-(2d), and Eqs. (3a) and (3b) are
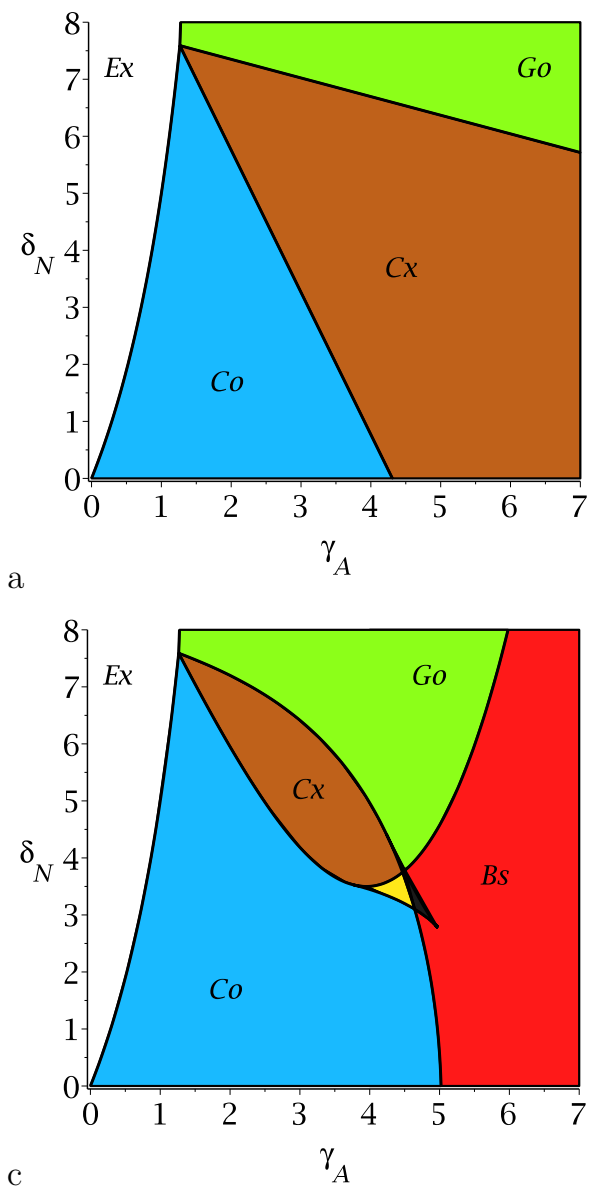

summarized in Fig. 2. The parameters under variation in the bifurcation diagrams are $\gamma_{A}$ (the deposition rate of atmospheric ammonia, on the horizontal axis), and $\delta_{N}$ (the outflux of nitrate with e.g. soil water, on the vertical axis). The other parameters are fixed at the values given in Table 3.

When there is no over-shading ( $\alpha_{C G}=\alpha_{G C}=0$, Fig. 2a) the bifurcation diagram displays four distinct regions of asymptotic behaviour. When $\gamma_{A}$ is too low while $\delta_{N}$ is too high neither of the species can exist (indicated by the white region marked by $E x$ ), i.e., not enough nitrogen enters the system while there is a strong leakage of nitrogen. For low values of both $\gamma_{A}$ and $\delta_{N}$ there is persistence of Calluna only (blue region marked by $C_{0}$ ). This corresponds to nutrient-poor conditions typical for heathlands. An increase in $\gamma_{A}$ results in the possibility for grass to invade the system, leading to coexistence of both species (brown region marked by $C x$ ). A further increase in $\gamma_{A}$ combined with a significant increase in $\delta_{N}$ results in the extinction of Calluna, leaving grass as the sole species (green region marked by Go).

With limited over-shading by both species $\left(\alpha_{C G}=\alpha_{G C}=0.0085\right.$, Fig. 2b) the bifurcation diagram remains roughly the same, except some of the boundaries have changed. The region for which only grass persists increases significantly, suggesting an increased competitive advantage for grass under conditions of mutual overshading. A shift from heathland to grassland under increased ammonia deposition is already possible for smaller values of $\delta_{N}$ with these settings.

With strong mutual over-shading $\left(\alpha_{C G}=\alpha_{G C}=0.015\right.$, Fig. $2 \mathrm{c}$ ) the bifurcation diagram changes considerably as compared to the
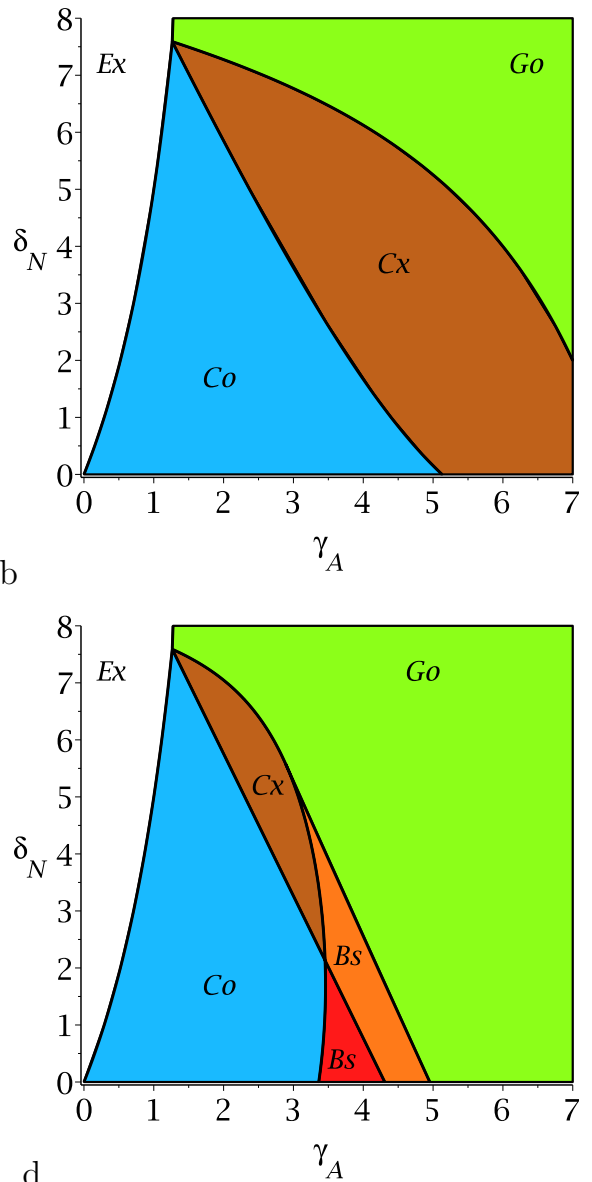

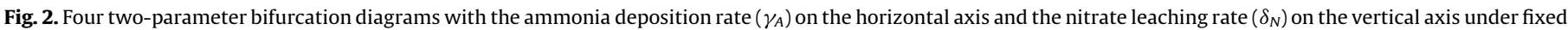

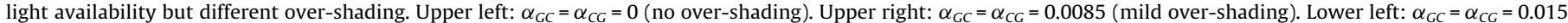

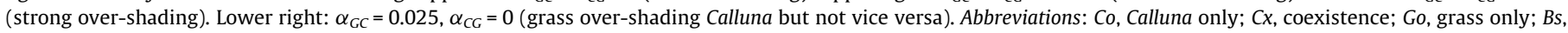
bistability. See main text for more explanation. 
case with no or limited mutual over-shading. The (brown) region of coexistence as the only stable state has shrunk considerably. Instead there are now additional regions with new types of behaviour. The first region is one with bistability (indicated by dark yellow), in which coexistence is one possible stable state and the alternative stable state is only Calluna. A second additional region is a small, tooth-shaped region with tristability (indicated by dark grey) adjacent to the dark yellow region, in which coexistence is one stable state, only Calluna is one alternative steady state, and only grass is the third possible stable state. The last new region is the most right region (indicated by red and marked with Bs) which is also a region of bistability. The two alternative stable states are only Calluna and only grass (i.e., there is no longer the possibility of coexistence).

To understand the origin of the tristability in the model a cross section of Fig. 2c is plotted in Fig. 3, where $\delta_{N}=3.2$ remains fixed while $\gamma_{A}$ is varied. Starting at the most left in both panels in Fig. 3 it is clear that the only steady state is that of only Calluna (indicated by $\mathrm{Co}$, which corresponds to the blue region). A tipping point is encountered at $\gamma_{A} \approx 4.5$ which is a tangent bifurcation. A mild increase in $\gamma_{A}$ is not necessarily sufficient for grass to invade because of priority effects (Drake, 1991): depending on initial conditions, the system evolves to either the state of Calluna only or to the coexistence steady state (indicated by $B s$, which corresponds to the dark yellow region). Furthermore, only in combination with an event that causes Calluna to die (e.g. because of disease or grazing) it might be possible for grass to establish, while a healthy Calluna canopy persists under mild nitrogen enrichment. A further increase in $\gamma_{A}$ leads to another tipping point, which is a transcritical bifurcation at $\gamma_{A} \approx 4.62$. At this point a third alternative steady state emerges, and we enter the region of tristability (indicated by $T s$, which corresponds to the dark grey tooth-shaped region). Finally, at $\gamma_{A} \approx 4.75$ another tipping point is crossed, which is a tangent bifurcation again. The stable state of coexistence disappears, and the two alternative states that are left are that of Calluna only and grass only (this region is marked by Bs, which corresponds to the red region).

It is suggested in the literature that Deschampsia can strongly affect Calluna in terms of over-shading but not the other way around (fact I). Therefore, the fourth case that is studied here is when there is only over-shading of Calluna by grass $\left(\alpha_{G C}=0.025\right.$, $\alpha_{C G}=0$, Fig. 2d). In this case the region of values for which only grass persists is significantly higher than for the cases in which the over-shading of both species is equal. There again are regions of bistability. The first region of bistability, adjacent to the region of only Calluna (indicated by red and marked by Bs), contains the two alternative stable states of Calluna only and grass only. Next to this region is the region of bistability in which the two alternative stable states are coexistence and grass only (indicated by dark orange and marked with $B s$ ). The steady state of coexistence disappears at the right boundary of this region in a tangent bifurcation. Contrary to the situation of strong mutual overshading, an asymmetrical over-shading leads to a large range of values for ammonia deposition for which grass is the dominant competitor.

\section{Discussion}

In this paper we have studied heathland transition to grassland by means of a dynamic model. The key concepts are over-shading and the use of the Synthesizing Unit to describe indirect competition for light, ammonium, and nitrate between the two main species, Calluna and the grass Deschampsia. In our model the transition from heathland to grassland can occur in different ways:

- By crossing a bifurcation under change in nitrogen deposition, much in agreement with the current dominant view that shifts are caused by increased atmospheric nitrogen levels.

- By crossing a bifurcation under change in the leaching of nitrate. This could for instance result from changes in precipitation.

- By crossing a separatrix in case there are more alternative stable states, where the separatrix is the stable manifold of an third, unstable steady state, that may be crossed after a perturbation (Schröder et al., 2005; Andersen et al., 2009). Such a crossing could be promoted by gap formation in heather canopy.

In our model we find large parameter regions for which there is coexistence between the two species under steady state conditions. Nitrogen enrichment alone is not sufficient to invoke a shift from heathland to grassland. Instead the combination of one-sided or at least asymmetrical over-shading and multiple nutrient limitation is crucial to explain mass-scale heathland conversion.

The above results differ from those found by existing annual time-step models that describe Calluna and Deschampsia dynamics under availability of light, nitrogen, and carbon, stochastic outbreaks of heather beetle, and the type of management (CALLUNA, Heil and Bobbink, 1993; HEATHSOL, Terry et al., 2004). Over-shading is considered in these models by making a distinction between a top layer and a lower layer of above-soil
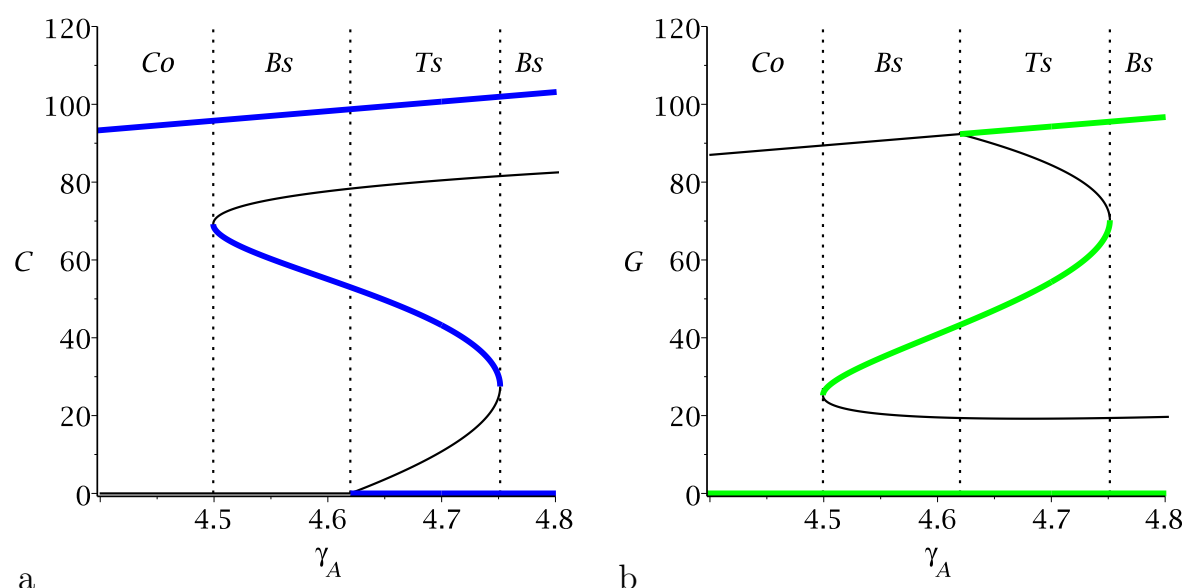

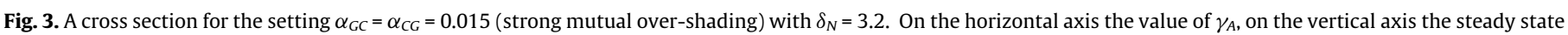

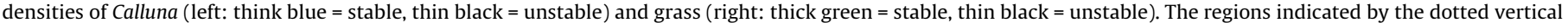

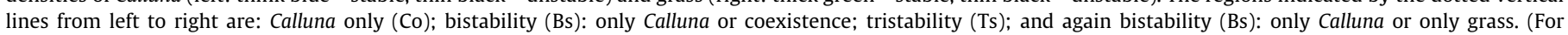
interpretation of the references to color in this figure legend, the reader is referred to the web version of the article.) 
biomass, where light availability in the lower layer depends on the level of irradiance not intercepted by the top layer and the relative proportions of leaf area of each species. Simulation results by HEATHSOL suggest that the accumulation of nitrogen that is deposited over the years is the main driver of heathland turning to grasslands, and furthermore that management aimed at litter removal proves to be the most effective option for reducing nitrogen enrichment.

The steady state results of our model can be matched to experimental findings. The results on co-existence between the two species seemed to match experimental observations in which both species could co-exist for periods of time relatively long compared to the time-scale of the ageing process of Calluna under similar species densities (Damgaard et al., 2009). The regions of bistability (the existence of at least two steady states, one free of Calluna and one free of grass) can be matched to related experiments in which species densities differed and the more dominant of the two species outcompeted the other (Damgaard et al., 2009).

The way of generating conditions of bistability in the presented model is by over-shading. Under conditions of significant overshading the two species can outcompete the other in the model, depending on the initial conditions. It has also been suggested that over-shading is just a one-sided interaction in which grasses overshade Calluna but not vice versa (Britton et al., 2003). When overshading is asymmetrical in our model Calluna can only survive under nutrient-poor conditions. Under nutrient enrichment already bistability occurs in which one possible stable state is a grass-only state. This would suggest there are conditions under which healthy Calluna canopy would persist under mild nutrient enrichment, while grass can outcompete Calluna when there are sufficient gaps in the canopy. These findings are in agreement with reported fact II (Alonso et al., 2001).

The canopy can be damaged in different ways. One option is grazing by the heather beetle ( $L$. suturalis). This is why some authors consider grazing already as a sufficient factor to lead to conversion from heathland to grassland (Berdowski, 1987). Grazing is more likely to be targeted towards grass when it is done by ungulates, and therefore other authors do not consider beetle grazing to be the dominant driver (Alonso et al., 2001). Another way of how damage to the canopy can occur is by winter frost or low temperature desiccation to Calluna shoots. Although nitrogen addition seems to actually improve frost tolerance in Calluna (Caporn et al., 1994), field survey results suggest that after large nitrogen depositions more winter damage occurs to Calluna canopy (Carroll et al., 1999).

Summarizing the above, our model results suggest that the combination of one-sided or at least asymmetrical over-shading with multiple nutrient limitation is required to explain sudden catastrophic shifts from heathland to grassland under increased nitrogen deposition. The results also suggest that canopy damage is required in order for grasses to establish under mildly increased nitrogen deposition. Our model results suggest that current management practices such as burning and mowing may not be appropriate to prevent heathland conversion to grassland. These practices result in canopy damage and may in fact aid the establishment of grass, in particular in view of the higher growth rates of grass compared to those of Calluna.

The hypothesis that the combination of canopy damage, mild nitrogen enrichment, and over-shading drives a shift from heathland to grassland is testable for example by applying different cutting patterns and rates in patches of heathland under different light and nitrogen application settings e.g. by using mesocosms. It should be noted in this regard that spatial structure is neglected in the current model. It is well-known from the literature that the explicit addition of a spatial structure in combination with dispersal of the species can generate spatial patterns (Malchow et al., 2008; Rietkerk and Van de Koppel, 2008). Such patterns may also become apparent in a mesocosm study for large enough patches. Future research may be aimed at implementing the model as a reaction-diffusion model and linking it to observations of spatial patterns.

While our key model finding is that over-shading plays a crucial role in the existence of tipping points and bistability in the system, there may be other explanatory or auxiliary factors behind the shift from heathland to grassland.

One mechanism to introduce bistability in the system and to possibly explain the heathland shift may be related to acidification. Discussions by different authors suggest that acidification of heathland by nitrogen is not likely to have a significant effect at some point as the soils are already acidic (Damgaard et al., 2014). The activity of nitrifying bacteria Nitrosomonas and Nitrobacter is significantly reduced in acidic mineral soils of $\mathrm{pH}<5.0$ (Gigon and Rorison, 1972). Experiments with plant growth under different $\mathrm{pH}$ conditions show that Deschampsia growth rates are not affected dramatically by $\mathrm{pH}$ under $\mathrm{NH}_{4}^{+}$enrichment, while growth rates decrease with decreasing $\mathrm{pH}$ under $\mathrm{NO}_{3}^{-}$enrichment (Gigon and Rorison, 1972). This suggests that acidification indeed may limit microbial activity, which would violate our assumption 3 , which says that conversion rates affected by microbial activity are not limiting. As the nitrogen enrichment of natural patches is mostly in the form of ammonia, the 'primary food source' of Deschampsia is not limited. However, enrichment by ammonium also leads to acidification, which leads to decreased microbial activity of nitrifying bacteria, which in turn results in less nitrate being available. In other words, the 'primary food source' of Calluna (nitrate) is affected in a nonlinear way by enrichment by ammonia, as ammonia is the precursor to nitrate but also affects its own conversion rate by affecting the microbial activity through acidification. This suggests that the heathland shift may be a cascaded or amplified tipping point resulting from acidification accompanying the nitrogen enrichment of natural areas, which presents a competitive advantage for grass.

In the model we have not discriminated between the types of dead material (litter) produced by Calluna and Deschampsia. Experiments with types of litter have shown that the nitrogen content of litter may be an important driver of the competition between grass and heather. While grass grows better on both types of litter than without litter, heather actually performs worse on litter from grass. In mixed cultures Deschampsia outcompetes Calluna except when there is no litter (Hofland-Zijlstra and Berendse, 2009). This asymmetrical feedback could present an alternative to the asymmetrical over-shading or an amplifying mechanism for it.

Despite some limitations the presented SU-based food web model of only two species at the same trophic level including overshading and multiple nutrient limitation is capable of explaining the shift from heathland to grassland under increased ammonia deposition. Its results correspond well with several reported experimental results and observed facts. In all studied model settings Calluna survives under nutrient-poor conditions, while grass is in general the better competitor under conditions of high nitrogen deposition or high leaching of nitrate. The over-shading itself is critical in generating alternative stable states in the model, while the asymmetry in the over-shading provides a rigorous mechanism to explain widespread shifts to grassland under nitrogen enrichment.

\section{Acknowledgements}

The research of GVV is part of the strategic research program KB-IV "Sustainable spatial development of ecosystems, landscapes, seas and regions" which has been funded by the Dutch Ministry of 
Economic Affairs and carried out by Wageningen UR, project number KB-14-002-026. We thank an anonymous reviewer for his/ her constructive comments on an earlier version of the paper.

\section{Appendix A. Functional response derivation}

In view of model foundation No. 3 we use a Synthesizing Unit (SU) formulation to adequately handle the co-limitation by light and nitrogen for each of the two species. The SU formulation (O'Neill et al., 1989; Kooi et al., 2004; Kooijman, 2010) is a suitable description for enzymatic reactions and trophic interactions alike. In this case a combined complementary-substitutable SU is required, where the complementary part represents the need for both light and nitrogen, and the substitutable part represents the observation that both ammonium $A$ and nitrate $N$ are suitable as nitrogen source. The SU is depicted in Fig. 4. Observe, that we need two similar SU descriptions, namely one for Calluna $(C)$ and one for grass $(G)$.

A key assumption in this derivation is that the interactions of the plant species $C, G$ with the nutrients $A, N, L$ (such as binding and handling rates) are much faster than the physiological processes (such as growth) as described in Eq. (1). The fluxes on the fast time scale are shown in Fig. 4. The (differential) equations describing these fluxes (with $\tau$ as the fast time variable $\tau \ll t$ ) are

$1=\theta_{\ldots .}+\theta_{\cdot A \cdot}+\theta_{L . .}+\theta_{\cdot \cdot N}+\theta_{L A .}+\theta_{L \cdot N}$

$\frac{d}{d \tau} \theta_{\cdot A \cdot}=b_{A} A(t) \theta \ldots-b_{L} L \theta_{\cdot A .}$,

$\frac{d}{d \tau} \theta_{L . .}=b_{L} L \theta \ldots-\left(b_{A} A(t)+b_{N} N(t)\right) \theta_{L . .}$,

$\frac{d}{d \tau} \theta_{\cdots N}=b_{N} N(t) \theta \ldots-b_{L} L \theta_{\cdots N}$,

$\frac{d}{d \tau} \theta_{L A .}=b_{A} A(t) \theta_{L \cdot .}+b_{L} L \theta_{\cdot A \cdot}-k_{L A} \theta_{L A .}$,

$\frac{d}{d \tau} \theta_{L \cdot N}=b_{N} N(t) \theta_{L \cdot .}+b_{L} L \theta_{\cdots \cdot N}-k_{L N} \theta_{L \cdot N}$,

where the state variables $\theta_{\times \times \times}$represent fractions of the state in which the SU can be. The SU represents a unit of biomass. The dynamics of $A, N$ are still a function of the slow time scale time variable $t$ (see Eq. (1)). Because of the possibility of (unequal) overshading we distinguish between $L_{G}$ and $L_{C}$, where $L_{C}$ is the light

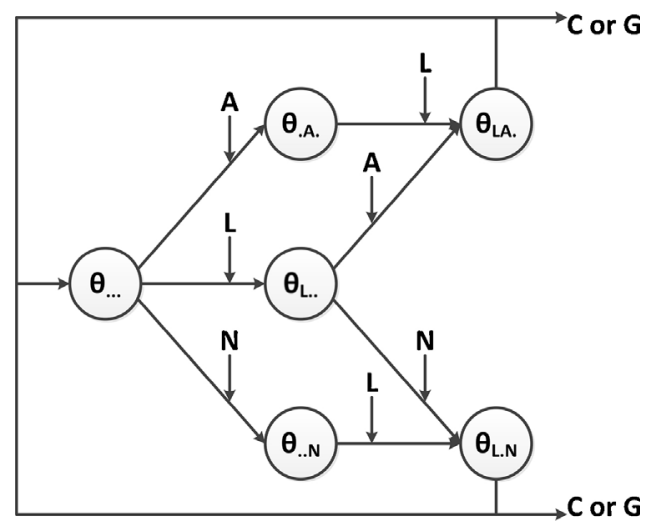

Fig. 4. A schematic depiction of the Synthesizing Unit for grass $(G)$ and Calluna $(C)$ used in the model. The symbols are given in Table 3 . The species can differ in their association rates for $A$ and $N$. availability in the SU for Calluna and $L_{C}$ the light availability in the SU for grass.

The quasi-steady state values for the different fractions are now found by solving Eq. (4) using software for symbolic calculations, such as MAPLE. This results in

$$
\begin{aligned}
& \theta_{\ldots .}^{*}=b_{L} L k_{L A} k_{L N}\left(b_{A} A+b_{N} N\right) \Theta_{\times}^{-1}, \\
& \theta_{\cdot A \cdot}^{*}=b_{A} A k_{L A} k_{L N}\left(b_{A} A+b_{N} N\right) \Theta_{\times}^{-1}, \\
& \theta_{L \cdot .}^{*}=b_{L}^{2} L^{2} k_{L A} k_{L N} \Theta_{\times}^{-1}, \\
& \theta_{\cdot . N}^{*}=b_{N} N k_{L A} k_{L N}\left(b_{A} A+b_{N} N\right) \Theta_{\times}^{-1}, \\
& \theta_{L A \cdot}^{*}=b_{A} A b_{L} L k_{L N}\left(b_{A} A+b_{L} L+b_{N} N\right) \Theta_{\times}^{-1}, \\
& \theta_{L \cdot N}^{*}=b_{L} L b_{N} N k_{L A}\left(b_{A} A+b_{L} L+b_{N} N\right) \Theta_{\times}^{-1},
\end{aligned}
$$

where $\Theta_{\times}$is the sum of the nominators of the quasi-steady state values of the $\operatorname{six} \theta_{\times \times \times}^{*}$ and still $A(t), L(t)$ and $N(t)$. Observe there are also two distinct $\Theta_{\times}$, one $\left(\Theta_{C}\right)$ for species $C$ and one $\left(\Theta_{G}\right)$ for species $G$. The parameters are given in Table 4 .

We call $f_{\times x}=\theta_{L \times x}^{*}$ (which is defined per unit of plant biomass) the scaled functional response, where $\theta_{L \times x}^{*}$ are given in Eqs. (5e)(5f). These expressions are used as functional responses in Eqs. (2a)(2d). Observe that the expression for $f_{\times \times}$is also a function of light density $L$ and is not equal to one as is generally the case. The expression of $f_{\times \times}$thus entails a fixed chemical composition of the resulting plant biomass after assimilation of the nutrients.

We furthermore have the following limit cases (where we take $\left.L_{C}=L_{G}=L\right)$

$\lim _{L \rightarrow \infty} f_{A}=\frac{b_{A} A k_{L N}}{b_{A} A k_{L N}+b_{N} N k_{L A}+k_{L A} k_{L N}}$,

$\lim _{L \rightarrow \infty} f_{N}=\frac{b_{N} N k_{L A}}{b_{A} A k_{L N}+b_{N} N k_{L A}+k_{L A} k_{L N}}$,

$\lim _{A \rightarrow \infty} f_{A}=\frac{b_{L} L}{b_{L} L+k_{L A}}=\frac{L}{L+K_{A}}$,

$\lim _{A \rightarrow \infty} f_{N}=0$

$\lim _{N \rightarrow \infty} f_{A}=0$

\begin{tabular}{|c|c|c|c|}
\hline Symbol & Dimension & Value & Description \\
\hline$\tau$ & $T$ & - & Time at the fast time-scale \\
\hline$b_{A C}$ & $M_{A}^{-1} L^{2} T^{-1}$ & 0.1 & Association rate for $A$ by Calluna \\
\hline$b_{L C}$ & $M_{L}^{-1} L^{2} T^{-1}$ & 0.1 & Association rate for $L$ by Calluna \\
\hline$b_{N C}$ & $M_{N}^{-1} L^{2} T^{-1}$ & 0.2 & Association rate for $N$ by Calluna \\
\hline$b_{A G}$ & $M_{A}^{-1} L^{2} T^{-1}$ & 0.1 & Association rate for $A$ by grass \\
\hline$b_{L G}$ & $M_{L}^{-1} L^{2} T^{-1}$ & 0.1 & Association rate for $L$ by grass \\
\hline$b_{N G}$ & $M_{N}^{-1} L^{2} \quad T^{-1}$ & 0.1 & Association rate for $N$ by grass \\
\hline$k_{L A C}$ & $T^{-1}$ & 0.1 & $\begin{array}{l}\text { Dissociation rate for production } \\
\text { of } C \text { from } A \text { and } L\end{array}$ \\
\hline$k_{L N C}$ & $T^{-1}$ & 0.4 & $\begin{array}{l}\text { Dissociation rate for production } \\
\text { of } C \text { from } N \text { and } L\end{array}$ \\
\hline$k_{L A G}$ & $T^{-1}$ & 0.5 & $\begin{array}{l}\text { Dissociation rate for production } \\
\text { of } G \text { from } A \text { and } L\end{array}$ \\
\hline$k_{L N G}$ & $T^{-1}$ & 0.2 & $\begin{array}{l}\text { Dissociation rate for production } \\
\text { of } G \text { from } N \text { and } L\end{array}$ \\
\hline
\end{tabular}

Table 4

Parameters and state variables of the fast time-scale equations for the derivation of the SYNTHESIZING UNIT (see also Table 3). Dimensions are expressed as SI dimensions: $T=$ time, $L=$ length, $M=$ mass. The underscores for mass $M$ indicate the type of mass. 
$\lim _{N \rightarrow \infty} f_{N}=\frac{b_{L} L}{b_{L} L+k_{L N}}=\frac{L}{L+K_{N}}$

In the limit cases $A \rightarrow 0$ and $N \rightarrow 0$ while $L_{C}=L_{G}=L$ these functional responses converge to a standard complementary SU. In turn, the limit cases $L \rightarrow 0$ and $A \rightarrow 0$ (or $N \rightarrow 0$ ) of the complementary SU give zero. The third and sixth limits are similar to the well-known Holling type II functional response, where $K_{\times}=k_{L \times} / b_{L}$ is called the half-saturation constant and where one species is consuming one nutrient $(L)$. The first two limits (unlimited light) reproduce the substitutable functional response with one species consuming two non-essential nutrients $A$ and $N$. Then the species can survive either consuming one of the two nutrients, or both. In our case these two versions are combined where on the one hand light $L$ is an essential nutrient, and on the other hand either ammonium $A$ or nitrate $N$, or both, are essential.

There are two functional responses on the slow time scale (incorporated in Eq. (1) with time variable $t$ ) for each of the two species, giving a total of four distinct functional responses. These are the flux from $\theta_{L A}$. to $\theta \ldots$, and the flux from $\theta_{L \cdot N}$ to $\theta \ldots$, as both provide the same product (i.e., biomass of $C$ or $G$ ). The scaled functional responses are dimensionless as $\theta_{\times \times \times}^{*}$ are dimensionless.

The scaled functional response expressions are now substituted into Eq. (1) where they are multiplied by the maximum ingestion rate denoted by $I_{\times \times} \propto k_{\times \times}$, and by $C$ or $G$, the biomass of the relevant plant species (since the functional response was defined per unit of plant biomass). The parameters $I_{\times \times}$represent the ingestion rates and are not dimensionless because they entail stoichiometric conversions (observe that we just assume a 1-on-1 conversion). In the main equations we refer to $f_{L A C}$ and $f_{L N C}$ for fluxes for Calluna (with again $L_{C}$ for light utility), and $f_{L A G}$ and $f_{L N G}$ for grass (and $L_{G}$ for light utility), respectively. We can rewrite this further by taking $K_{\times}=k_{L \times} / b_{L}$ (as mentioned above), where the two parameters $I_{\times \times}$(the maximum ingestion rate) and $K_{\times}$(the halfsaturation constant) have a well-known interpretation in the Holling type II functional response.

\section{References}

Aerts, R., Berendse, F., De Caluwe, H., Schmitz, M., 1990. Competition in heathland along an experimental gradient of nutrient availability. Oikos 57, 310-318.

Alonso, I., Hartley, S.E., Thurlow, M., 2001. Competition between heather and grasses on Scottish moorlands: interacting effects of nutrient enrichment and grazing regime. J. Veg. Sci. 12, 249-260.

Andersen, T., Carstensen, J., Hernández-García, E., Duarte, C.M., 2009. Ecological thresholds and regime shifts: approaches to identification. Trends Ecol. Evol. 24, 49-57.

Bazykin, A.D., 1998. Nonlinear Dynamics of Interacting Populations. World Scientific, Singapore.

Berdowski, J.J.M., 1987. Transition from heathland to grassland initiated by the heather beetle. Plant Ecol. 72, 167-173.

Bluman, G.W., Kumei, S., 1989. Symmetries and Differential Equations. SpringerVerlag, New York.

Bobbink, R., Braun, S., Nordin, A., Power, S., Schütz, K., Strengbom, J., Weijters, M., Tomassen, H., 2011. Review and revision of empirical critical loads and doseresponse relationships. In: Proceedings of an Expert Workshop, Noordwijkerhout, 23-25 June 2010, RIVM Report: 680359002.

Boettiger, C., Ross, N., Hastings, A., 2013. Early warning signals: the charted and uncharted territories. Theor. Ecol. 6, 255-264.

Britton, A., Marrs, R., Pakeman, R., Carey, P., 2003. The influence of soil-type, drought and nitrogen addition on interactions between Callunavulgaris and Deschampsiaflexuosa: implications for heathland regeneration. Plant Ecol. 166, 93-105.

Cadbury, C.J., 1992. Grazing and other management of upland vegetation: a review with special reference to birds. RSPB Conserv. Rev. 7, 12-20.

Caporn, S.J.M., Risager, M., Lee, J.A., 1994. Effect of nitrogen supply on frost hardiness in Callunavulgaris (L.) Hull. New Phytol. 128, 461-468.

Carroll, J.A., Caporn, S.J.M., Cawley, L., Read, D.J., Lee, J.A., 1999. The effect of increased deposition of atmospheric nitrogen on Callunavulgaris in upland Britain. New Phytol. 141, 423-431.
Damgaard, C., Riis-Nielsen, T., Schmidt, I.K., 2009. Estimating plant competition coefficients and predicting community dynamics from non-destructive pinpoint data: a case study with Callunavulgaris and Deschampsiaflexuosa. Plant Ecol. 201, 687-697.

Damgaard, C., Strandberg, M., Kristiansen, S.M., Nielsen, K.E., Bak, J.L., 2014. Is Ericatetralix abundance on wet heathlands controlled by nitrogen deposition or soil acidification? Environ. Pollut. 184, 1-8.

Di, H.J., Cameron, K.C., 2002. Nitrate leaching in temperate agroecosystems: sources, factors and mitigating strategies. Nutr. Cycl. Agroecosyst. 46, $237-256$.

Doedel, E.J., Oldeman, B., 2009. AuTo07p: Continuation and Bifurcation Software for Ordinary Differential Equations. Concordia University, Montreal, Canada.

Drake, J.A., 1991. Community-assembly mechanics and the structure of an experimental species ensemble. Am. Nat. 137, 1-26.

Folke, C., Carpenter, S., Walker, B., Scheffer, M., Elmqvist, T., Gunderson, L., Holling, C.S., 2004. Regime shifts, resilience, and biodiversity in ecosystem management. Annu. Rev. Ecol. Evol. Syst. 35, 557-581.

Gherardi, L.A., Sala, O.E., Yahdjian, L., 2013. Preference for different inorganic nitrogen forms among plant functional types and species of the Patagonian steppe. Oecologia 173 (3), 1075-1081.

Gigon, A., Rorison, I.H., 1972. The response of some ecologically distinct plant species to nitrate- and to ammonium-nitrogen. J. Ecol. 60, 93-102.

Guckenheimer, J., Holmes, P., 1985. Nonlinear Oscillations, Dynamical Systems and Bifurcations of Vector Fields. Springer, Berlin.

Heil, G.W., Bobbink, R., 1993. 'Calluna': a simulation model for evaluation of impacts of atmospheric nitrogen deposition. Ecol. Model. 68, 161-182.

Heil, G.W., Diemont, W.H., 1983. Raised nutrient levels change heathland into grassland. Vegetation 53, 113-120.

Hofland-Zijlstra, J.D., Berendse, F., 2009. Effects of litters with different concentrations of phenolics on the competition between Callunavulgaris and Deschampsiaflexuosa. Plant Soil 327, 131-141.

Iason, G.R., Hester, A.J., 1993. The response of heather (Callunavulgaris) to shade and nutrients - predictions of the carbon-nutrient balance hypothesis. J. Ecol. 81, $75-80$.

Kooi, B.W., 2003. Numerical bifurcation analysis of ecosystems in a spatially homogeneous environment. Acta Biotheor. 51, 189-222.

Kooi, B.W., Kuijper, L.D.J., Kooijman, S.A.L.M., 2004. Consequences of symbiosis for food web dynamics. J. Math. Biol. 49, 227-271.

Kooi, B.W., Van Voorn, G.A.K., Pada Das, K., 2011. Stabilization and complex dynamics in a predator-prey model with predator suffering from an infectious disease. Ecol. Complex. 8, 113-122

Kooijman, S.A.L.M., 2010. Dynamic Energy Budget Theory for Metabolic Organisation, 3rd ed. Cambridge University Press, Cambridge.

Kot, M., 2001. Elements of Mathematical Ecology. Cambridge University Press, Cambridge, UK

Kuznetsov, Y.A., 2004. Elements of Applied Bifurcation Theory: Applied Mathematical Sciences, vol. 112. Springer-Verlag, New York.

Malchow, H., Petrovskii, S.V., Venturino, E., 2008. Spatiotemporal Patterns in Ecology and Epidemiology: Theory, Models, and Simulation. Chapman \& Hall/CRC Press, London.

Maplesoft, Waterloo, Ontario, Canada. http://www.maplesoft.com/.

McCann, K., Hastings, A., Huxel, G.R., 1998. Weak trophic interactions and the balance of nature. Nature 395, 794-798.

O’Neill, R.V., DeAngelis, D.L., Pastor, J.J., Jackson, B.J., Post, W.M., 1989. Multiple nutrient limitations in ecological models. Ecol. Model. 46, 147-163.

Pitcairn, C.E.R., Fowler, D., Grace, J., 1995. Deposition of fixed atmospheric nitrogen and foliar nitrogen content of Bryophytes and Calluna vulgaris (L.) Hull. Environ. Pollut. 88, 193-205.

Power, S.A., Ashmore, M.R., Cousins, D.A., Sheppard, L.J., 1998. Effects of nitrogen addition on the stress sensitivity of Callunavulgaris. New Phytol. 138, 663-673.

Ri, X., Prentice, I.C., 2008. Terrestrial nitrogen cycle simulation with a dynamic global vegetation model. Glob. Change Biol. 14, 1745-1764.

Rietkerk, M., Van de Koppel, J., 2008. Regular pattern formation in real ecosystems. Trends Ecol. Evol. 23, 169-175.

Scheffer, M., Carpenter, S.R., 2003. Catastrophic regime shifts in ecosystems: linking theory to observation. Trends Ecol. Evol. 18, 648-656.

Scheffer, M., Bascompte, J., Brock, W.A., Brovkin, V., Carpenter, S.R., Dakos, V., Held, H., Van Nes, E.H., Rietkerk, M., Sugihara, G., 2009. Early-warning signals for critical transitions. Nature 461, 53-59.

Schlüter, M., McAllister, R.R.J., Arlinghaus, R., Bunnefeld, N., Eisenack, K., Hölker, F., Milner-Gulland, E.J., Müller, B., Nicholson, E., Quaas, M., Stöven, M., 2012. New horizons for managing the environment: a review of coupled social-ecological systems modeling. Nat. Resour. Model. 25, 219-272.

Schröder, A., Persson, L., De Roos, A.M., 2005. Direct experimental evidence for alternative stable states: a review. Oikos 110, 3-19.

Seydel, R., 2010. Practical Bifurcation and Stability Analysis, 3rd ed. Springer/ Dordrecht Heidelberg, New York/London.

Terry, A.C., Ashmore, M.R., Power, S.A., Allchin, E.A., Heil, G.W., 2004. Modelling the impacts of atmospheric nitrogen deposition on Calluna-dominated ecosystems in the UK. J. Appl. Ecol. 41, 897-909.

Van der Eerden, L.J., Dueck, T.A., Berdowski, J.J.M., Greven, H., Van Dobben, H.F. 1991. Influence of $\mathrm{NH}_{3}$ and $\left(\mathrm{NH}_{4}\right)_{2} \mathrm{SO}_{4}$ on heathland vegetation. Acta Bot. Neerl 40, 281-296.

Van Voorn, G.A.K. van, Hemerik, L., Boer, M.P., Kooi, B.W., 2007. Heteroclinic orbits indicate overexploitation in predator-prey systems with a strong Allee effect. Math. Biosci. 209, 451-469. 
Van Voorn, G.A.K. van, Kooi, B.W., Boer, M.P., 2010. Ecological consequences of global bifurcations in some food chain models. Math. Biosci. 226, 120-133.

Velders, G.J.M., Aben, J.M.M., Van Jaarsveld, J.A., Van Pul, W.A.J., De Vries, W.J., Van Zanten, M.C., 2010. In Dutch: Grootschalige stikstofdepositie in Nederland Herkomst en ontwikkeling in de tijd (In English: Large-Scale Nitrogen Deposition in the Netherlands - Origin and Development Through Time) PBL Report: $500088007 / 2010$.
Von Oheimb, G., Power, S.A., Falk, K., Friedrich, U., Mohamed, A., Krug, A., Boschatzke, N., Härdtle, W., 2010. N:P ratio and the nature of nutrient limitation in Calluna-dominated heathlands. Ecosystems 13, 317-327.

Wiggins, S., 1990. Introduction to Applied Nonlinear Dynamical Systems and Chaos. Springer, New York.

Worrall, F., Clay, G.D., 2014. The potential use of heather, Callunavulgaris, as a bioenergy crop. Biomass Bioenergy 64, 140-151. 